\title{
Disentangling the effects of age and global change on Douglas fir growth
}

\author{
Dario Ravaioli ${ }^{(1)}$, \\ Fabrizio Ferretti ${ }^{(2)}$, \\ Federico Magnani ${ }^{(1)}$
}

\begin{abstract}
Recent changes commonly observed in forests growth could be the result of a combination of different climatic and non-climatic factors, such as rising atmospheric $\left[\mathrm{CO}_{2}\right]$, temperature changes, atmospheric $\mathrm{N}$ deposition and drought stress. These effects are difficult to assess, however, due to the superimposition of age-related changes. After removing age effects through a novel approach, this study quantifies the effects on tree growth of global change, and assesses the relationship with individual environmental drivers and their relative importance. Generalized Additive Mixed Models (GAMMs) were applied to decouple the non-linear effects of age and co-occurring environmental changes on basal area increments (BAl) series, as derived from tree rings in a Pseudotsuga menziesii stand chronosequence of four different age classes $(65-, 80-, 100-$ and 120 -year-old). The model could explain about $57 \%$ of the overall variation in BAl as a function of age and a selected set of predictors, including water availability in the current summer and at the end of previous growing season; together with age, winter-spring mean temperature was found to be the most important predictor. After accounting for age-related effects, a significant decrease in BAI was observed in Douglas fir over the last decades. No significant impact of atmospheric $\left[\mathrm{CO}_{2}\right]$ and atmospheric $\mathrm{N}$ deposition were detected.
\end{abstract}

Keywords: Pseudotsuga menziesii, Basal Area Increments, Long-term Trends, Global Change, GAMM, Chronosequence ported such a positive link, although stressing the importance of concomitant related factors, for example disturbance history or an increasing length of the vegetative period (McMahon et al. 2010). Indeed, interactions with other environmental variables such as atmospheric $\mathrm{N}$ deposition (Magnani et al. 2007) are expected to play a determinant role especially in resource-limited environments. Moreover, a parallel increase in transpiration rates as a result of increasing temperatures could negate this positive effect, in particular in droughtprone areas (Gómez-Guerrero et al. 2013). There is therefore a pressing need to understand which key drivers have been affecting forest growth rates, and quantify the magnitude of their effects. Even in the absence of controlled experiments, the analysis of long-term trends in tree growth can help elucidate the role of changes in
(1) Dipartimento di Scienze e Tecnologie Agro-Alimentari, Alma Mater Studiorum - Università di Bologna, via Fanin 44, I-40127 Bologna (Italy); (2) CREA Research Centre for Forestry and Wood, v.le Santa Margherita 80, I-52100 Arezzo (Italy)

@ Dario Ravaioli (dario.ravaioli3@unibo.it)

Received: Sep 01, 2017 - Accepted: Mar 11, 2019

Citation: Ravaioli D, Ferretti F, Magnani F (2019). Disentangling the effects of age and global change on Douglas fir growth. iForest 12: 246-253. - doi: 10.3832/ifor2620-012 [online 201905-03]

Communicated by: Marco Borghetti different environmental factors, since the growth pattern of a tree is the result of surrounding conditions, as well as ontogenetic processes (Babst et al. 2014). Treering widths (TRW) area direct measure of stem increments, hence the inspection of their time series provides a reliable and datable source of data that can be used to investigate high and low-frequency variability in forest growth trends. In order to highlight the environmental-related signals enclosed in tree-ring series, however, the superimposed age-(or size-) related signal must be first removed. An age-size related decline in TRW is generally observed with increasing age, due not only to geometrical constraints but also to hydraulic limitations related to tree height. In response to the increased hydraulic resistance of longer stems and branches and to the increased gravitational potential opposing the ascent of water, trees show a progressive reduction in stomatal conductance at old age and tend to reduce photosynthesis and growth (Mencuccini et al. 2005). Basal area increments (BAI), on the contrary, generally display an increase with age, followed by a gradual stabilization. Canonical procedures applied in dendrochronological studies remove this age-related biological trend through the application of de-trending techniques, such as spline or negative exponential fitting (Peters et al. 2015). However, a consequence of this correction is the removal of low-frequency signals associated to tree-ring series (Cook et al. 1995). Preserving low-frequency variations is of 
Fig. 1 - Location of the study site (red square).

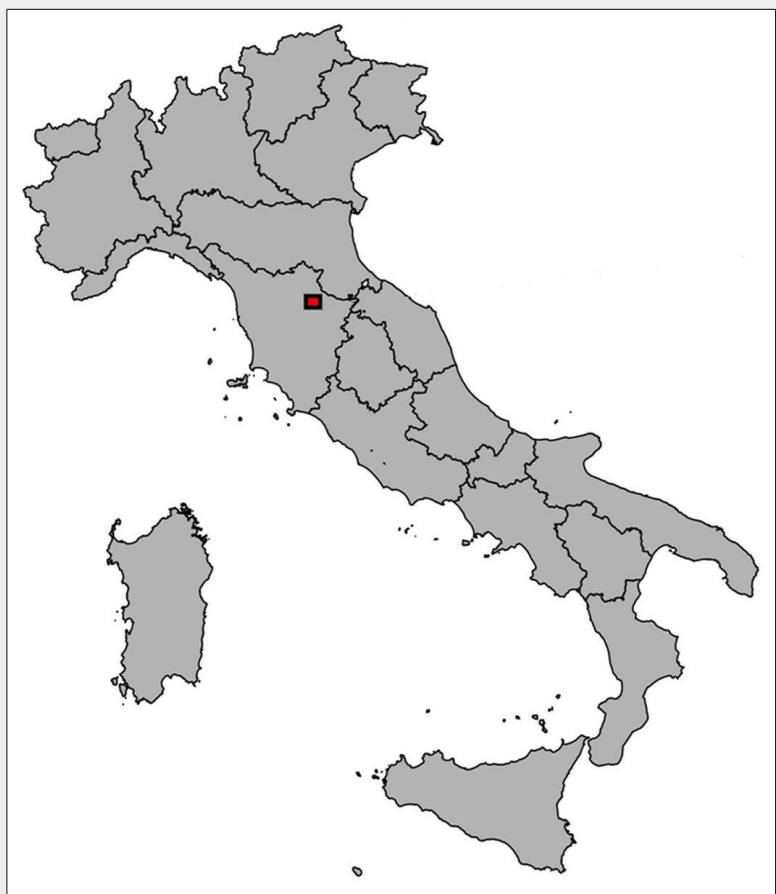

fundamental importance if the objective of the analysis is to investigate long-term trends (Esper et al. 2002). In this study, Generalised Additive Mixed Models (GAMMs) were used as a tool to detect and separate the effect of different variables, both biological (i.e., age- or size-related) and environmental, on tree-ring trends in a Douglas fir (Pseudotsuga menziesii (Mirb.) Franco) chronosequence. This non-linear regression technique is a ceteris paribus form of analysis, looking at the effects of a single factor while keeping remaining factors constant (Rita et al. 2016). Tree age-size effects can be then considered as a simple additive variable, making it possible to disentangle the superimposed effects of other environmental covariates (Camarero et al. 2015). Therefore, such a model can provide an alternative to traditional de-trending procedures, with the advantage of retaining low frequency variability in the time series. In addition, GAMMs preserve the non-linearity of the relationship between the response and the explanatory variables, in contrast with the assumption of linearity commonly made in dendroecological studies.

The aim of the present study is therefore to understand if Douglas fir has been affected by the changing environmental pressure in a long-term perspective, looking at which variable or combination of variables has driven any observed changes in growth rates.

\section{Materials and methods}

\section{Study area}

This study was performed in a Douglas fir plantation located in the Vallombrosa Forest, in the Apennine mountain range near Florence, Italy ( $43^{\circ} 43^{\prime} 59.6^{\prime \prime} \mathrm{N}, 11^{\circ} 33^{\prime} 16.9^{\prime \prime}$ E - Fig. 1). The region has a Mediterranean climate without significant summer droughts; mean annual precipitation is approximately $1400 \mathrm{~mm}$, of which only about $5 \%$ occur in summer months $(72.48 \mathrm{~mm})$. Mean annual temperature is $9.8^{\circ} \mathrm{C}$. The soils, derived from the Macigno del Chianti sandstone series, vary between Humic Dystrudept and Typic Humudept (Soil Survey
Staff 2014) in the younger and older stands, respectively, indicating similar soil conditions at the site. Douglas fir is a nonindigenous evergreen species which was imported from the Pacific Coast of the United States during the last decades of the $19^{\text {th }}$ century; it was chosen for the present study because of its high economic importance. The sampled areas are part of the experimental permanent plot network managed by CREA Research Centre for Forestry and Wood (Arezzo, Italy), and include the oldest experimental plots established in Italy at the beginning of the $20^{\text {th }}$ century (Pavari 1916). A chronosequence of plots was selected for the study; a chronosequence is here defined as a set of even-aged stands growing under the same environmental conditions and differing only for their age (Walker et al. 2010). The chronosequence approach made it possible to disentangle the effects of environmental changes from co-occurring changes in age and size. By comparing rings formed on the same calendar year (i.e., under identical environmental conditions) by trees of different age along the chronosequence, the approach makes it possible to highlight the real effect of age. On the other hand, considering rings formed at the same cambial age but in different calendar years, it is possible to isolate the true effect of varying environmental conditions.

The chronosequence comprises four different age classes $(65,80,100$ and 120 years), covering the longest temporal interval that can be achieved in Italy for this species. The mean characteristics of the four age classes are summarized in Tab. 1. Seven plots were sampled that were consistent for management, aspect and elevation. Two plots were selected for each age class, in order to ensure replication; however this was not possible for the oldest class, as only one stand of this age was present in the area. In all plots, only dominant trees were chosen for the analysis, in order to avoid competition effects; repeated forest surveys on the same plots ensured the permanence of their dominant status at least for the last 40 years, as confirmed by an analysis of the Daniels' competition index (Daniels \& Burkhart 1986 see Fig. S1 in Supplementary material), in-

Tab. 1 - Mean characteristics of plots in the the Vallombrosa Douglas fir chronosequence. Mean \pm standard error.

\begin{tabular}{|c|c|c|c|c|c|c|c|}
\hline \multirow{3}{*}{$\begin{array}{l}\text { Variable } \\
\text { Plot (code) }\end{array}$} & \multicolumn{7}{|c|}{ Age-class } \\
\hline & \multirow{2}{*}{$\begin{array}{c}120 \\
1\end{array}$} & \multicolumn{2}{|c|}{100} & \multicolumn{2}{|c|}{80} & \multicolumn{2}{|c|}{65} \\
\hline & & 2 & 3 & 4 & 5 & 6 & 7 \\
\hline Age (yrs) & $117 \pm 0.7$ & $95 \pm 0.7$ & $94 \pm 1.6$ & $82 \pm 0.4$ & $81 \pm 0.9$ & $64 \pm 0.8$ & $62 \pm 0.6$ \\
\hline Distance to the pith $(\mathrm{cm})$ & $1.9 \pm 0.8$ & $2.4 \pm 0.9$ & $4.0 \pm 1.3$ & $1.7 \pm 0.5$ & $1.2 \pm 0.3$ & $2.1 \pm 0.7$ & $1.7 \pm 0.6$ \\
\hline Years to the pith (rings) & $3.4 \pm 1.3$ & $3.6 \pm 0.9$ & $5.8 \pm 1.4$ & $2.6 \pm 0.4$ & $1.8 \pm 0.4$ & $2.8 \pm 0.7$ & $2.8 \pm 0.9$ \\
\hline Elevation (m a.s.l.) & 900 & 1100 & 1009 & 1095 & 1280 & 1113 & 1113 \\
\hline Aspect & $\mathrm{N}$ & $\mathrm{N}$ & SW & NE & $\mathrm{NE}$ & SW & SW \\
\hline Top diameter $(\mathrm{cm})$ & 68.9 & 60.8 & 67.5 & 58.2 & 61.5 & 50.3 & 43.3 \\
\hline Top height (m) & 51.3 & 47.2 & 54.4 & 49.9 & 44.3 & 39.9 & 39.8 \\
\hline Stand density (trees ha-1) & 30 & 375 & 380 & 360 & 280 & 600 & 550 \\
\hline
\end{tabular}


dependently of the management regime adopted (Fig. S2). Thinnings at the site are mainly from below, removing suppressed or intermediate trees which compete little with dominant trees. The use of survey data makes it possible to avoid potential sampling biases which occur when the currently largest-diameter trees are wrongly considered to have always been in the dominant class (Cherubini et al. 1998).

\section{Tree-ring data}

A total of 35 trees were sampled in the spring and fall of 2013, five from each of the aforementioned plots. One single core was extracted at breast height from each tree with a $5.1 \mathrm{~mm}$ Pressler borer (Haglöf, Sweden). The extracted cores were then air-dried and polished with progressively finer sandpaper (60- to 300-grit), so as to distinguish annual ring boundaries. Ring width series were measured on images taken by a long-focal high definition camera (Canon, Japan) with the CooRecorder ${ }^{\circledR}$ image analysis software (Cybis Elektronik and Data AB, Sweden) with $0.01 \mathrm{~mm}$ resolution. Samples were visually cross-dated against a reference curve, between and within the series using a correlation coefficient, Gleichläufigkeit values and Student's $t$-test as indices. The closest tree ring chronology available in the International Tree Rings Data Base (ITRDB) was used as a reference for pointer year detection; the selected dataset (Schweingruber $\mathrm{FH}$ Mount Falterona - ABAL - ITAL008) refers to an Abies alba chronology from Mount Falterona ( $23 \mathrm{~km}$ from Vallombrosa). As a further check, a reference curve was developed using the Douglas fir dataset itself by the "leave-one-out" methodology, starting from samples with a high correlation with the previous reference curve used. The quality of cross-dating was then checked and cross-correlation analysis was performed using the $\mathrm{CDendro}^{\oplus}$ software ( $\mathrm{Cy}$ bis Elektronikand Data $A B$ ) and the $R$ "dpIR" package (Bunn 2008). When the extracted core did not reach the pith of the tree, the length to the centre was estimated using the curvature of the last complete ring, and the number of missing rings was calculated by dividing this distance by the average of last five-year ring widths (Applequist 1958). These values were then checked against the year of plantation establishment, according to the forest management plan. Ring widths were then converted into basal area increments (BAI), as the latter allows to compensate for the age-size effect associated with the geometry of stems, especially at young age, while preserving low-frequency variability (Biondi 1999). Moreover, BAl is considered a better proxy of growth compared with radial increments (Bouriaud et al. 2005). It was calculated as (eqn. 1):

$$
B A I=\pi \cdot\left(r_{t}^{2}-r_{t-1}^{2}\right)
$$

where $r_{t}$ is the stem radius in a given year and $r_{t-1}$ is the value corresponding to the previous year.

\section{Environmental data}

Daily records of mean, maximum and minimum temperatures and precipitation were obtained from the Regional Hydrological Service of the Tuscany Region (SIR) and then averaged for each month. Measurements for the 1922-2013 period were derived from the closest weather station, located at less than $3 \mathrm{~km}$ from sampled plots, and integrated with the dataset obtained by Gandolfo \& Sulli (1990) for the 1898-1922 period.

The selection of what months to include in the analysis was based on the correlation between monthly climatic variables and ring width index (RWI), de-trended by the negative exponential curve method, using the bootstrapped static correlation function available in the $\mathrm{R}$ "Treeclim" package (Zang \& Biondi 2015 - Fig. S3 in Supplementary material). Subsequently, individual significant variables were pooled if contiguous (e.g., mean temperature of January, February and March, hereafter referred to as JFM temperature).

Mean annual data of air $\mathrm{CO}_{2}$ concentration were obtained from the NOAA Earth System Research Laboratory, as recorded at the Mauna Loa observatory in Hawaii from 1959 to present day, and from McCarroll \& Loader (2004) for the 1898-1958 period. Average annual values of $\mathrm{N}$ oxide (NOy) and ammonium (NHx) atmospheric deposition (both dry and wet deposition) for the period from 1898 to 2013 were extracted from the NCAR global data set managed by IGAC-SPARC CCMI (ChemistryClimate Model Initiative; available for download at http://blogs.reading.ac.uk/cc $\mathrm{mi} /$ - Hegglin et al., in preparation). These $\mathrm{N}$ deposition data were generated with the NCAR atmospheric transport model ( $\mathrm{Na}$ tional Center for Atmospheric Research), which provides gridded (resolution of $2.0^{\circ}$ $\times 2.25^{\circ}$, longitude $\times$ latitude) temporal simulations of the chemical composition of the atmosphere. The resulting environmental dataset covers the entire time span investigated (1898 to 2013). In order to evaluate the potential effects of drought stress, the Standardized Precipitation Evapotranspiration Index (SPEI - Vicente-Serrano et al. 2010) was also included in the analysis. SPEI considers the sensitivity to changes in evapo-transpiration demand and precipitation (P-PET) at different timescales, computing the cumulative influence of $n$ previous months on the water deficit/surplus of the month of interest; P-PET was derived from the Thornthwaite's equation (Thornthwaite 1948). The best SPEI timescale was selected based on the correlation between tree-ring width index series (RWI), and the SPEI values computed for each month with a timescale in the range 1-24 (Vicente-Serrano et al. 2014).

\section{Data analysis}

As tree growth exhibits strong non-linear patterns caused by both biological (i.e., hydraulic limitations, ontogenetic effects) and environmental drivers (i.e., changes in $\mathrm{CO}_{2}$, temperature, precipitation, etc.), generalized additive models (Hastie \& Tibshirani 1990) were applied to identify the shape of the relationship between BAI and predictor variables. GAMMs are non-linear regression models that express non-parametrically the dependent variable as the sum of smooth functions of independent variables. Such a model relaxes any a priori assumptions of the functional relationship between response and predictors, so resulting in a more flexible range of application. In general, a GAMM can be expressed as:

$$
y_{i}=X_{i} \beta+s_{1} x_{i 1}+s_{2} x_{i n}+\cdots+Z_{i} b+v_{i}+\varepsilon_{i}
$$

where $y_{i}$ is a response variable, $\beta$ is an unknown vector of fixed effects, $X_{i}$ is a row of a fixed effects model matrix; $s_{1}, \ldots, s_{n}$ are smooth functions of covariates $x_{i} ; Z_{i}$ is a row of a random effects model matrix, $b_{i}$ is the unknown vector of random effects, $v_{i}$ is an error term with an auto-regressive $\operatorname{AR}(1)$ correlation structure and $\varepsilon_{\mathrm{i}}$ are residuals with normal distribution and constant variance (Wood 2006). In our study, the GAMM was applied to log-transformed BAI data, so as to correct for heteroscedasticity in ring-width data. A cubic penalized spline was used as smooth function. This is the result of the simultaneous fitting of basis functions (i.e., natural cubic spline) penalized to achieve the optimal degree of smoothness, so avoiding data over-fitting. The amount of penalizations was automatically computed by the maximum likelihood estimation (ML - Wood 2006). The selection of covariates was performed by a stepwise backward process. Candidates for removal were identified based on their lower approximate $\mathrm{p}$-values and the model resulting after the subtraction of such variables was compared with the previous one based on Bayesan information criterion (BIC). This index was used instead of the Akaike information criterion (AIC) because it is less conservative and more useful to assess the simpler model in confirmatory analysis; in model selection, the BIC provides a better opportunity to understand which pool of variables generated the real data (Aho et al. 2014). All of the GAMM analyses were performed with the "mgcv" package (Wood 2006) of the R statistical suite (R Core Team 2017). In order to deal with temporal autocorrelation, a simple first order $A R(1)$ autoregressive structure for errors was introduced, even if this kind of pre-whitening process can potentially remove some of the underlying long-term growth trend when applied on tree ring series (Yue et al. 2011). The concurvity level (i.e., the generalization of co-linearity in non-linear models) was also checked to assess a potential correlation among vari- 
ables (Flg. S4). Finally, model results were tested to ensure that the assumptions of normal distribution of observations and absence of heteroscedasticity and independence of residuals were respected (Fig. S5 in Supplementary Material).

\section{Results}

\section{Wood increments}

The general statistics of the tree-ring chronologies are summarized in Tab. 2. All of the trees used in this study were satisfactorily cross-dated and no missing rings were detected. The quality of the dataset is also confirmed by other indices. The mean series inter-correlation (CC) which represents the strength of the common signal shared by all series is about 0.5 , while the expressed population signal (EPS - Wigley et al. 1984) is above the conventional threshold of 0.85 used to define the acceptability of a chronology. This index confirms the goodness of cross-dating and the possibility to use this dataset for further analysis. Furthermore, mean sensitivity (MS), which is an index of year-to-year variability related to climate and/or disturbances, was also checked; a value ranking about 0.2 shows an adequate sensitive series, normally useful for climatic correlation analysis.

The basal area increments of trees belonging to the different age classes are presented in Fig. $2 a$ and Fig. 2b, plotted against calendar year and cambial age, respectively. Taking a synchronic perspective, BAI shows a distinct increase over the last century, with values for some trees reaching above $10,000 \mathrm{~mm}^{2} \mathrm{yr}^{-1}$. In the 1950-2010 period covered by all four age classes, younger trees seem to present slower growth rates than older individuals. Such an age-related pattern is confirmed by the diachronic analysis of Fig. 2b, which suggests a continuous increase in basal area increments until an age of 90 years; the sharp drop at the far end of the 100and 120-year age classes is an artifact, due

Tab. 2 - Descriptive statistics for tree-ring width (TRW) and ring width index (RWI) chronologies of the different age-classes. (MW): mean ring width $(\mathrm{mm})$; $(\mathrm{SD})$ : standard deviation (mm); (MS): mean sensitivity; (AR1): first order autocorrelation; (ESP): expressed population signal; (CC): series inter-correlation (with std. dev. in brackets).

\begin{tabular}{cccllll}
\hline \multirow{2}{*}{ Age-class } & TRW & & & & RWI & \\
\cline { 2 - 7 } & MW & SD & MS & AR1 & EPS & CC \\
\hline 65 & 3.54 & 1.66 & 0.1488 & 0.8506 & - & - \\
80 & 3.41 & 2.01 & 0.1871 & 0.855 & - & - \\
100 & 3.60 & 1.77 & 0.198 & 0.7519 & - & - \\
120 & 3.32 & 1.25 & 0.2004 & 0.7088 & - & - \\
\hline Total & 3.49 & 1.73 & 0.1811 & 0.8034 & 0.855 & 0.50 \\
& & & & & & $(0.08)$ \\
\hline
\end{tabular}

to the declining number of trees reaching the oldest age in each class. The diachronic perspective also reveals, however, that global change also contributes to the observed time dynamics, as young trees are currently growing less than similarly aged trees 40 to 60 years ago.

\section{Model output}

In order to assess possible changes of growth rates over time, independent of the co-occurring effects of ontogenetic factors, tree basal area increments (BAl) were modeled as (eqn. 3):

$$
\log (B A I)=s(\text { Age })+s(\text { Time })+Z_{i} \cdot b+v_{i}+\varepsilon_{i}
$$

where $s$ (Age) is the cambial age effect and $s$ (Time) represents all of the environmental effects cumulated into a single global change variable, varying over time. The age-related effect (Fig. 3a) displays the expected shape, with a steep increase at early age in the first part of the curve, followed by a less pronounced growth, and an apparent flattening at an age of 90. After the subtraction of the age-related signal, the trend in the BAl component associated with global change (Fig. 3b) shows an initial increase, two culminations around the 'zos and the '8os of the last century, a lower growth in between and a subse- quent decrease until the first decade of this century, which is significant at the $95 \%$ level.

As a second step, in order to partition to individual drivers the effect so far attributed to global change, seasonal climatic (temperature and SPEI) and geochemical variables (atmospheric $\left[\mathrm{CO}_{2}\right]$ and $\mathrm{N}$ deposition) were added to the model instead of time per se.

In a preliminary analysis, the SPEI index most correlated with RWI was found to be centered on August with a two-months timescale (hence referred to as $\mathrm{SPEI}_{\mathrm{JA}}$ ), with a Pearson's correlation coefficient of 0.46 (Fig. 4); this suggests a short-time response to drought, which is typical of a highly productive coniferous forest in such a mesic environment. A two-months timescale was therefore assumed for SPEI in all subsequent analyses.

After a procedure of backward stepwise variable selection (Tab. 3), the resulting model was specified as follow (eqn. 4):

$$
\begin{aligned}
\log (B A I) & =s(\text { Age })+s\left(S P E I_{J A}^{t}\right) \\
& +s\left(S P E I_{A S}^{t-1}\right)+s\left(T_{J F M}^{t}\right) \\
& +Z_{i} \cdot b+v_{i}+\varepsilon_{i}
\end{aligned}
$$

where Age is the age-size effect associated with variations in cambial age, $\mathrm{SPEI}_{\mathrm{JA}}{ }^{\mathrm{t}}$ and $\mathrm{SPEI}_{S A}{ }^{\mathrm{t}-1}$ represent the SPEI (indicative of

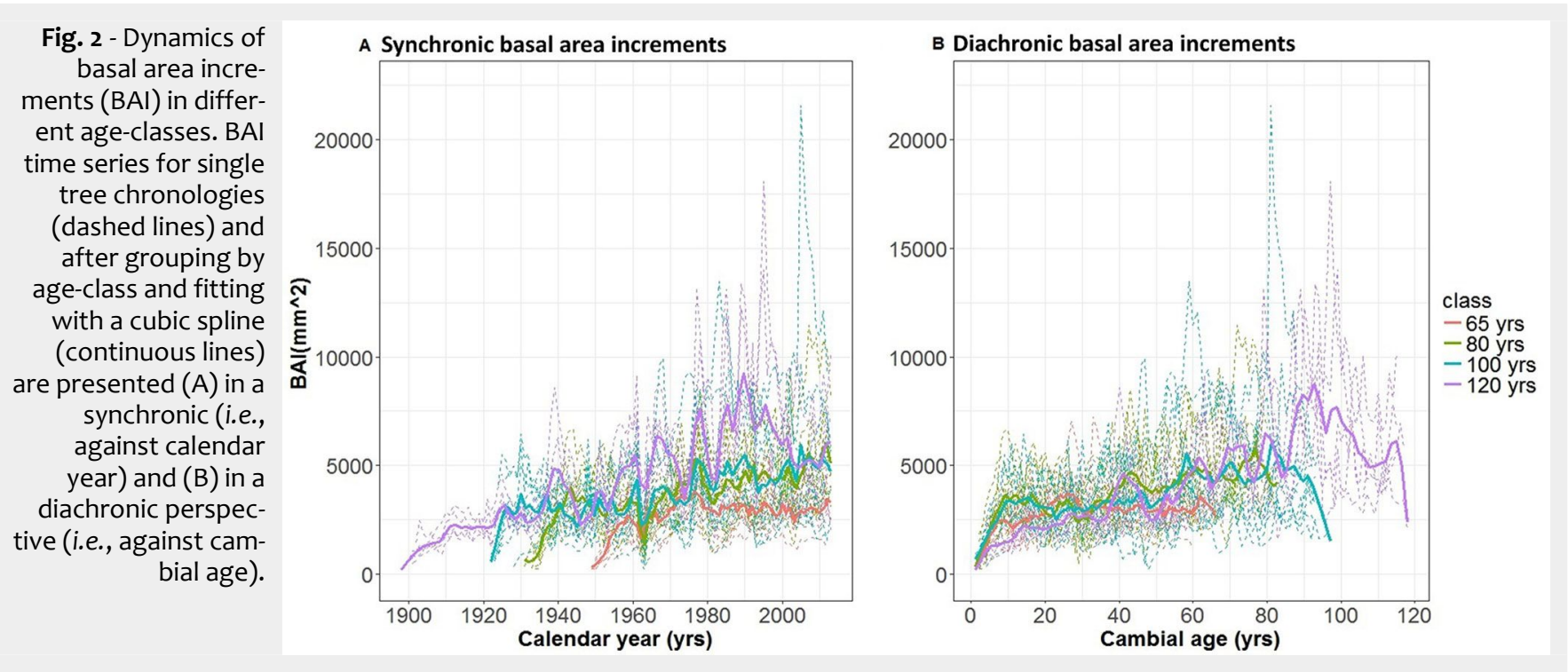


Fig. 3 - GAMM analysis of the independent effects of age and time on basal area increments (BAl - see eqn. 3). (a) Trend of $\log (\mathrm{BAI})$ as a function of age alone after correcting for timerelated effects. On the $x$-axis is cambial age (years), on $y$-axis is $s$ (Age), the component of $\log (\mathrm{BAI})$ explained by age, dimensionless and centered around o. (b) Trend of $\log (\mathrm{BAI})$ as a function of time

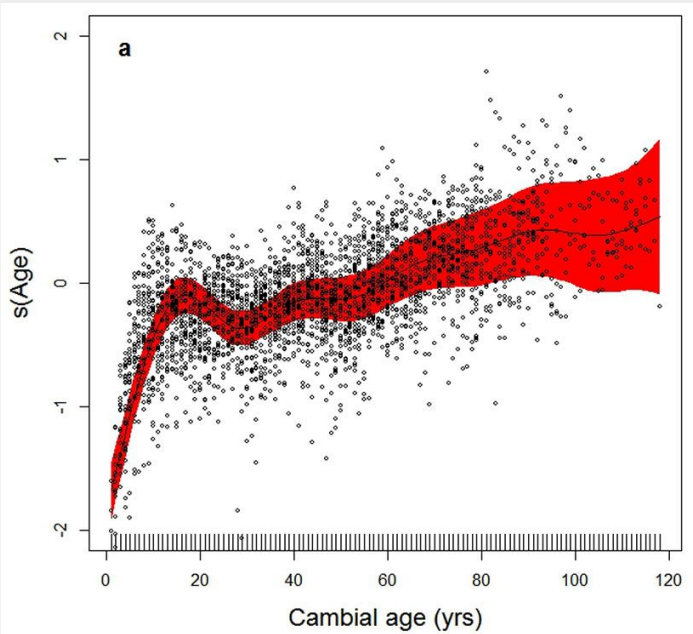

alone, after correcting for age-related effects. On $x$-axis is calendar year, on $y$-axis is s(Time), the component of log(BAI) explained by time per se, dimensionless and centered around 0 . Points represent partial residuals from the fitted function and the shaded areas indicate the $95 \%$ prediction interval of fitted adaptive splines. The GAMM model of eqn. 3 was applied to log-transformed BAI data, so as to correct for heteroscedasticity.

Fig. 4 - Heatmap of SPEI correlation with ring-width index (RWI) series. Correlation (Pearson's coefficient) between de-trended tree-ring index (RWI) and the Standardized Precipitation Evapotranspiration Index (SPEI) computed for different months (on the $y$-axis) and temporal scales ranging from 1- to 24 months.

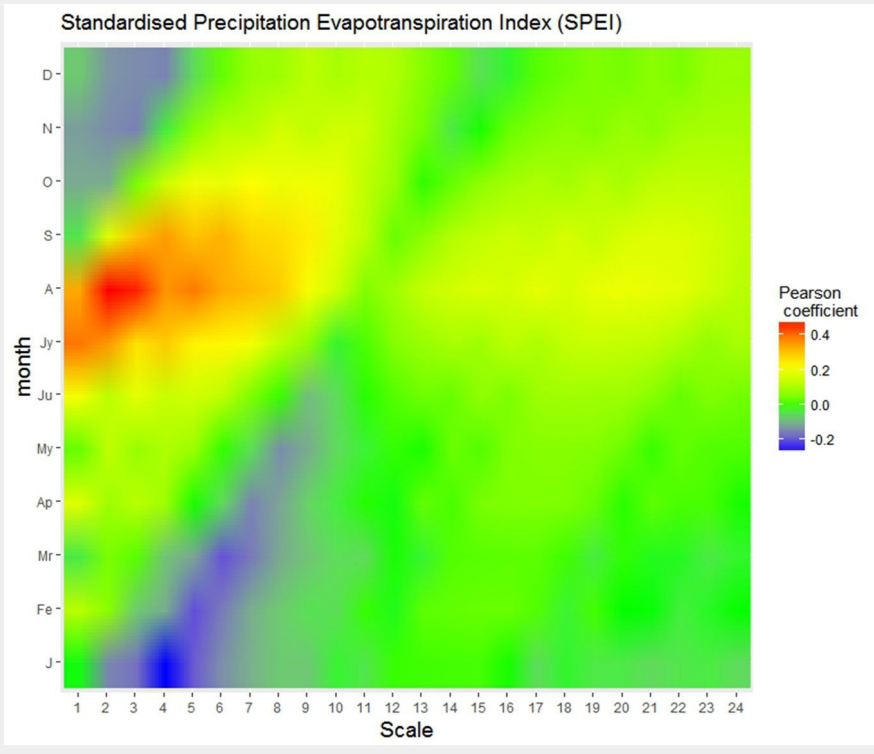

Tab. 3 - Differences in the Bayesan information criterion $(\triangle B I C)$ of alternative log(BAI) GAMM models. The selected model with the lowest $\mathrm{BIC}$ is marked with an asterisk $\left({ }^{*}\right) . \triangle \mathrm{BIC}$ was calculated as the difference between the BIC of each model and that of the selected model. (Age): cambial age; $\left(\mathrm{CO}_{2}\right)$ : atmospheric $\left[\mathrm{CO}_{2}\right]$; (Ndep): atmospheric N deposition; (SPEI): Standardized Precipitation Evapotranspiration Index (SPEI) in July and August of the current year; (SPEI $\mathrm{t}_{-1}$ ): SPEI in August and September of the previous year; $(T)$ : mean temperature of January-March period of the current year. All models are subsets of the full model (mo).

\begin{tabular}{|c|c|c|c|}
\hline Model fixed effects & Model & BIC & $\Delta \mathrm{BIC}$ \\
\hline Age $+\mathrm{CO}_{2}+\mathrm{Ndep}+\mathrm{SPEI}+\mathrm{SPEI}_{\mathrm{t}-1}+\mathrm{T}$ & $\mathrm{m} 0$ & -40.6947 & 20.6109 \\
\hline $\mathrm{CO}_{2}+\mathrm{Ndep}+\mathrm{SPEI}+\mathrm{SPEI}_{\mathrm{t}-1}+\mathrm{T}$ & $\mathrm{m} 1$ & 164.3962 & 225.7018 \\
\hline Age + Ndep + SPEI + SPEI $_{t-1}+\mathrm{T}$ & $\mathrm{m} 2$ & -46.7642 & 14.5414 \\
\hline Age $+\mathrm{CO}_{2}+\mathrm{SPEI}+\mathrm{SPEI}_{\mathrm{t}-1}+\mathrm{T}$ & $\mathrm{m} 3$ & -24.8838 & 36.4219 \\
\hline Age $+\mathrm{CO}_{2}+\mathrm{Ndep}+\mathrm{SPEI}_{\mathrm{t}-1}+\mathrm{T}$ & $\mathrm{m} 4$ & 49.7032 & 111.0088 \\
\hline Age $+\mathrm{CO}_{2}+\mathrm{Ndep}+\mathrm{SPEI}+\mathrm{T}$ & m5 & -17.9830 & 43.3226 \\
\hline Age $+\mathrm{CO}_{2}+$ Ndep $+\mathrm{SPEI}+\mathrm{SPEI}_{\mathrm{t}-1}$ & m6 & 144.5604 & 205.8660 \\
\hline $\mathrm{Ndep}+\mathrm{SPEI}+\mathrm{SPEI}_{\mathrm{t}-1}+\mathrm{T}$ & $\mathrm{m} 7$ & 202.7464 & 264.0520 \\
\hline Age $+\mathrm{SPEI}+\mathrm{SPEI} \mathrm{I}_{\mathrm{t}-1}+\mathrm{T}$ & $\mathrm{m} 8$ * & -61.3056 & - \\
\hline Age + Ndep $+\mathrm{SPEI}_{\mathrm{t}-1}+\mathrm{T}$ & m9 & 43.6166 & 104.9222 \\
\hline Age +Ndep +SPEI +T & $\mathrm{m} 10$ & -40.8651 & 20.4405 \\
\hline Age + Ndep + SPEI + SPEI $\left.\right|_{t-1}$ & $\mathrm{~m} 11$ & 117.4654 & 178.7710 \\
\hline $\mathrm{SPEI}+\mathrm{SPEI}_{\mathrm{t}-1}+\mathrm{T}$ & $\mathrm{m} 12$ & 339.8094 & 401.1150 \\
\hline Age $+\mathrm{SPEI}_{\mathrm{t}-1}+\mathrm{T}$ & $\mathrm{m} 13$ & 32.7605 & 94.0661 \\
\hline
\end{tabular}


Tab. 4 - Generalized additive mixed model (GAMM) results for the relationship between the logarithm of basal area increments (BAI) and climatic and biological factors in Pseudotsuga menziesii, as presented in eqn. 4. (edf): effective degrees of freedom; $(F)$ : F-test for variance explained; $(P)$ : $p$-values; $\left(R^{2}\right.$-adj): adjusted regression coefficient of the model.

\begin{tabular}{|c|c|c|c|c|}
\hline Factor & $e d f$ & $F$ & $P$ & $R^{2}$-adj \\
\hline Age & 8.479 & 57.273 & $<2 e-16$ & - \\
\hline $\mathrm{SPEI}_{J A}{ }^{\mathrm{t}}$ & 5.53 & 20.607 & $<2 \mathrm{e}-16$ & - \\
\hline$S P E I_{A S}{ }^{t-1}$ & 7.473 & 11.255 & $2.58 \mathrm{e}-16$ & - \\
\hline$T_{\text {JFM }}{ }^{t}$ & 5.859 & 35.25 & $<2 \mathrm{e}-16$ & - \\
\hline $\mathrm{s}($ series $)$ & 25.682 & 3.165 & $9.02 e-15$ & - \\
\hline Whole model & - & - & - & 0.564 \\
\hline
\end{tabular}

water availability and drought stress) of the current summer (July and August) and of the end of the previous growing season (August and September), respectively, and $\mathrm{T}_{\mathrm{JFM}}{ }^{\mathrm{t}}$ is the mean temperature of January, February and March of the current year. In addition to age, the latter appears to be the most important environmental factor explaining the long-term growth trend in the Douglas fir chronosequence (F-test $=$ 35.25), followed by the SPEI index for the ongoing season (F-test $=20.607$ ) and the SPEI index representing water availability at the end of previous growing season ( $\mathrm{F}$ test $=11.255)$. All variables exhibit a signifi cant p-value at 0.001 level (Tab. 4), with a global adjusted $R^{2}$ for the whole model of 0.564 .

\section{Discussion}

The primary purpose of this study was to assess if any changes in growth rates have occurred over the last century in Douglas fir stands growing in the northern Apennines, after correcting for age-related patterns. The analysis of age-adjusted longterm trends indeed demonstrates a significant decrease in the productivity of this species from its peak value in the 1980 s. These findings appear to be consistent with several other studies that looked at forest growth changes in central Apennines (Piovesan et al. 2008), in the Mediterranean region by and large (Linares et al. 2010) and in other European areas (Vitas \& Zeimavičius 2006). The increase in summer drought resulting from increasing temperatures in recent years was generally found to have had a negative effect on growth, in association with co-varying factors, such as stand dynamics, competition and pests. These could exacerbate the role of the imbalance in water availability and overcome the potentially positive effects of the in- crease in the length of the growing season induced by higher temperatures and of the rise in atmospheric $\left[\mathrm{CO}_{2}\right]$, as well as of atmospheric $\mathrm{N}$ deposition. The general trend recorded in this study can be partially explained by examining the shape of the relationship between significant environmental factors and BAI. The effect of age displays, after an initial abrupt increase, a successive phase of rather constant rise and an apparent stabilization of growth at advanced age, largely consistent with what already observed in the preliminary analysis. The quasi-linear positive relationship between growth and mean winter-spring temperature (Fig. $5 \mathrm{~d}$ ) probably reflects the beneficial effect that high temperatures have at mountain sites, by reducing frost damage, snow accumulation and maintaining significant carbon assimilation during the dormant season, even at minimum photosynthetic rates (Emmingham \& Waring 1977), as well as inducing a longer vegetative season. Summer water availability (Fig. 5b), which is related to both precipitation and transpiration demand, is the third most important variable affecting the behavior of this species in the long-term, conditioning its growth performance (Beedlow et al. 2013) and distribution (Rehfeldt et al. 2014). Air dryness, which is also known to affect Douglas fir, was not in cluded as a potential driver in the present study due to a lack of suitable information. Water availability at the end of the previous growing season (August-September Fig. 5c) was also expected to have a positive effect on growth, since early-wood width is related to the amount of carbon
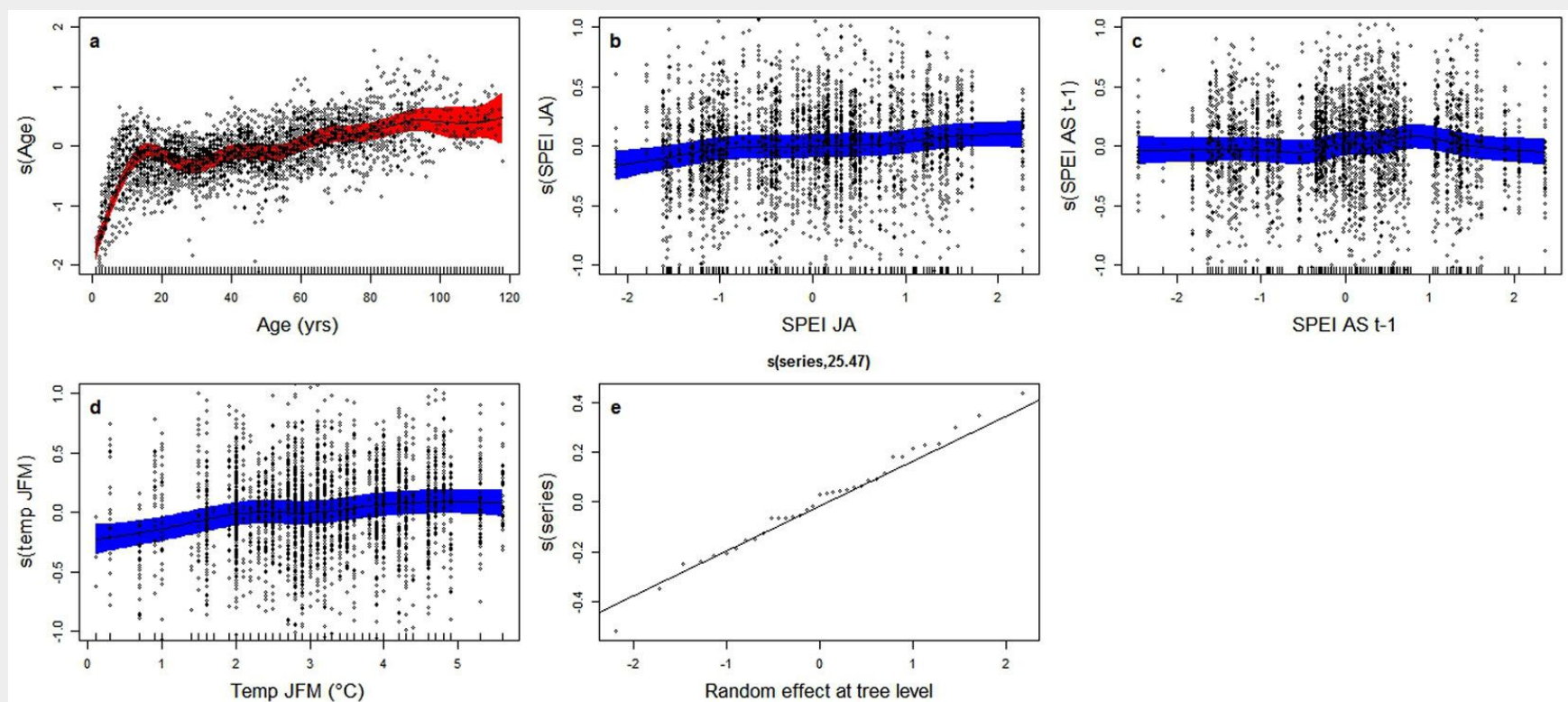

Fig. 5 - GAMM analysis of the independent effects of individual drivers on basal area increments (BAI - see eqn. 4). Generalized additive model (GAMM) results show the component of $\log (\mathrm{BAI})$ (dimensionless and centered around 0 ) explained by individual environmental and biological factors remaining after the backward model selection procedure: (a) cambial age; Standardized Precipitation Evapotranspiration Index computed over (b) July and August of the current year (SPEI JA) and (c) August and September of the previous year $\left(\mathrm{SPEI}_{\mathrm{AS}}{ }^{\mathrm{t}-1}\right)$; and (d) mean temperature over January, February and March (Temp $\left.{ }_{\mathrm{JFM}}\right)$. Points represent partial residuals from the fitted function and the shaded areas indicate the $95 \%$ prediction interval. The GAMM model was applied to log-transformed BAI data, so as to correct for heteroscedasticity. 
storage reserves built-up in the preceding year, which are subject to remobilisation in the first phase of vegetative growth (Lee et al. 2016). The shape of the relationship in Fig. $5 c$, however, suggests no negative effects of late-summer water deficit but on the contrary a slightly significant detrimental effect of water surplus. This behavior could be associated with the reduction of solar radiance, due to intense precipitation which can lead to an earlier end of the vegetative period.

The lack of evidence of a fertilization effect of $\mathrm{CO}_{2}$ is in agreement with previous studies (Lévesque et al. 2014) and could lead to different conclusions, depending on the processes involved. From a biological perspective, for example, both longterm photosynthetic acclimation (Medlyn et al. 1999) and a shift in allocation of assimilated $\mathrm{C}$ to faster-turnover pools such as fine roots or canopy foliage (Korner 2005) are possible explanations; taking a more biogeochemical perspective, this lack of response could also be attributed to the emergence of nutrient limitations, as nutrient availability cannot keep up with increasing $C$ assimilation (Oren et al. 2001).

It is important to recognize, however, that our results could be affected by a number of potential artifacts. First of all, the lack of $\mathrm{C} \mathrm{CO}_{2}$ fertilization effect could be due to the addition of the AR(1) structure for autocorrelation, since atmospheric $\left[\mathrm{CO}_{2}\right]$ is very similar from year to year and its incremental effects could be falsely attributed to previous year's growth.

Our assumption of no competition effects could also have biased the results. The growth of shade intolerant trees is significantly affected by stand density, especially in even-aged stands. Although the sampled trees have long maintained their dominant status (see Supplementary material) and should be therefore considered exempt from severe competition and growth suppression, we cannot exclude the presence of a positive influence of thinning (i.e., release effect - Fernàndez-deUna et al. 2016), which is recognized to enhance tree growth also at advanced age (Martìnez-Vilalta et al. 2006).

The impact of drought events could also have been insufficiently represented by the rather crude approach applied in the study. Finally, it should be mentioned that, when non-stationary forcing factors (i.e., atmospheric $\left[\mathrm{CO}_{2}\right]$ and $\mathrm{N}$ deposition) co-vary, it is difficult to disentangle their individual effects on long-term tree growth, and this complication increases with the complexity of the model (Carrer \& Urbinati 2006).

\section{Conclusions}

The combination of the chronosequence approach with Generalized Additive Mixed Models appears to have real potential to disentangle the superimposed non-linear biological and environmental effects affecting tree growth. By avoiding any detrending with an a priori model structure, the technique results in long-term trend preservation, which is fundamental to better understand past environmental effects and to predict the future behavior of forests in a changing world.

Given the importance of Douglas fir as a timber species, the ongoing decrease in growth performance illustrated by this study for the northern Apennines could have relevant implications from a management perspective. For this reason, understanding which factors have been determining such a trend is particularly important. Our model, despite the rather low amount of variance explained and the simplicity of the model structure, considering only a limited number of variables, allows us to draw some conclusions. The impact of summer water availability, which is projected to decrease in the Mediterranean region (IPCC 2014), could be responsible to a considerable extent for the observed decrease in growth rates in recent decades, due to the increase in magnitude and frequency of drought events. The positive effect ascribable to the extension of the growing season, as a result of increasing winter-spring temperatures, which should have promoted stem growth in the past, may no longer be able to counterbalance this summer drought stress effect. Especially in the absence of a positive effect of fertilization by rising atmospheric $\left[\mathrm{CO}_{2}\right]$ and $\mathrm{N}$ deposition, the observed trend can be expected to be exacerbated in the future.

\section{Acknowledgments}

We thank NOAA (ITRDB and ESRL) and the Regional Hydrological Service of the Tuscany Region (SIR), for providing the environmental data used in this study; also the Ufficio Territoriale Carabinieri per la Biodiversità di Vallombrosa which kindly provided sampling permission.

This work was carried out within the framework of the Convention between the Department of Agricultural and Food Sciences of the University of Bologna and the CREA Research Centre for Forestry and Wood.

\section{References}

Aho K, Derryberry D, Peterson T (2014). Model selection for ecologists: the worldview of AIC and BIC. Ecology 95: 631-636. - doi: 10.1890/131452.1

Ainsworth EA, Long SP (2005). What have we learned from 15 years of free-air $\mathrm{CO}_{2}$ enrichment (FACE)? A meta-analytic review of the responses of photosynthesis, canopy properties and plant production to rising $\mathrm{CO}_{2}$. New Phytologist 165: 351-71. - doi: 10.1111/j.1469-8137.2004. 01224.x

Applequist MB (1958). A simple pith locator for use with off-centre increment cores. Journal of Forestry 56: 141.

Babst F, Alexander MR, Szejner P, Bouriaud O, Klesse S, Roden J, Ciais P, Poulter B, Frank D, Moore DJP, Trouet V (2014). A tree-ring perspective on the terrestrial carbon cycle. Oe- cologia 176: 307-322. - doi: 10.1007/s00442-0143031-6

Beedlow PA, Lee EH, Tingey DT, Waschmann RS, Burdick CA (2013). The importance of seasonal temperature and moisture patterns on growth of Douglas-fir in western Oregon, USA. Agricultural and Forest Meteorology 169: 174-185. doi: 10.1016/j.agrformet.2012.10.010

Biondi F (1999). Comparing tree-ring chronologies and repeated timber inventories as forest monitoring tools. Ecological Applications 9: 216-227. - doi: 10.1890/1051-0761(1999)009[0216: CTRCAR]2.0.CO;2

Bouriaud O, Bréda N, Dupouey J-L, Granier A (2005). Is ring width a reliable proxy for stembiomass increment? A case study in European beech. Canadian Journal of Forest Research 35: 2920-2933. - doi: 10.1139/x05-202

Bunn AG (2008). A dendrochronology program library in R (dplR). Dendrochronologia 26: 115124. - doi: 10.1016/j.dendro.2008.01.002 Camarero JJ, Gazol A, Galván JD, Sangüesa-Barreda G, Gutiérrez E (2015). Disparate effects of global-change drivers on mountain conifer forests: warming-induced growth enhancement in young trees vs. $\mathrm{CO}_{2}$ fertilization in old trees from wet sites. Global Change Biology 21: 738749. - doi: 10.1111/gcb.12787

Carrer M, Urbinati C (2006). Long-term change in the sensitivity of tree-ring growth to climate forcing in Larix decidua. New Phytologist 170: 861-872. - doi: 10.1111/j.1469-8137.2006.01703.x Cherubini P, Dobbertin M, Innes J (1998). Potential sampling bias in long-term forest growth trends reconstructed from tree rings: a case of study from Italian Alps. Forest Ecology and Management 109: 103-118. - doi: 10.1016/S03781127(98)00242-4

Cook ER, Briffa KR, Meko DM, Graybill DA, Funkhouser G (1995). The "segment length curse" in long tree-ring chronology development for palaeoclimatic studies. The Holocene 5: 229-237. - doi: 10.1177/095968369500500211 Daniels RF, Burkhart HE (1986). A comparison of competition measures for predicting growth of loblolly pine trees. Canadian Journal of Forest Research 16: 1230-1237. - doi: 10.1139/x86-218 Emmingham WH, Waring RH (1977). An index of photosynthesis for comparing forest sites in western Oregon. Canadian Journal of Forest Research 7: 165-174. - doi: 10.1139/x77-023

Esper J, Cook ER, Schweingruber FH (2002). Low-frequency signals in long tree-ring chronologies for reconstructing past temperature variability. Science 295: 2250-2253. - doi: 10.1126/ science.1066208

Fernàndez-de-Una L, Mcdowell NG, Canellas I, Gea-Izquierdo G (2016). Disentangling the effect of competition, $\mathrm{CO}_{2}$ and climate on intrinsic water-use efficiency and tree growth. Journal of Ecology 104: 678-690. - doi: 10.1111/13652745.12544

Gandolfo C, Sulli M (1990). Vallombrosa 1872 1989: serie ultracentenaria di misure di precipitazioni e di temperatura in ambiente forestale. [Vallombrosa 1872-1989: precipitation and temperature ultracentenary series measurament in forest environment]. Annali dell'Istituto Sperimentale per la Selvicoltura 21: 147-181. [in Italian]

Gómez-Guerrero A, Silva LCRR, Barrera-Reyes M, 
Kishchuk B, Velázquez-Martínez A, Martínez-Trinidad T, Plascencia-Escalante FO, Horwath WR (2013). Growth decline and divergent tree ring isotopic composition $\left(\delta^{13} \mathrm{C}\right.$ and $\left.\delta^{18} \mathrm{O}\right)$ contradict predictions of $\mathrm{CO}_{2}$ stimulation in high altitudinal forests. Global Change Biology 19: 1748-1758. doi: 10.1111/gcb.12170

Hastie TJ, Tibshirani RJ (1990). Generalized additive models. In: "Monographs on statistics and Applied Probability". Chapman and Hall/CRC, New York, USA, pp. 4.

IPCC (2014). Climate change 2014 impacts, adaptation, and vulnerability. Part B: regional aspects (Barros VR, Field CB eds). Cambridge University Press, Cambridge, UK, pp. 1160.

Korner C (2005). Carbon flux and growth in mature deciduous forest trees exposed to elevated $\mathrm{CO}_{2}$. Science 309: 1360-1362. - doi: 10.1126/ science.1113977

Lee EH, Beedlow PA, Waschmann RS, Tingey DT, Wickham C, Cline S, Bollman M, Carlile C (2016). Douglas-fir displays a range of growth responses to temperature, water, and Swiss needle cast in western Oregon, USA. Agricultural and Forest Meteorology 221: 176-188. - doi: 10.1016/j.agrformet.2016.02.009

Lévesque $M$, Siegwolf $R$, Saurer $M$, Eilmann $B$, Rigling A (2014). Increased water-use efficiency does not lead to enhanced tree growth under xeric and mesic conditions. New Phytologist 203: 94-109. - doi: 10.1111/nph.12772

Linares JC, Camarero JJ, Carreira JA (2010). Competition modulates the adaptation capacity of forests to climatic stress: Insights from recent growth decline and death in relict stands of the Mediterranean fir Abies pinsapo. Journal of Ecology 98: 592-603. - doi: 10.1111/j.1365-2745.2010.0 1645.x

Magnani F, Mencuccini M, Borghetti M, Berbigier $\mathrm{P}$, Berninger F, Delzon S, Grelle A, Hari P, Jarvis PG, Kolari P, Kowalski AS, Lankreijer $H$, Law BE, Lindroth A, Loustau D, Manca G, Moncrieff JB, Rayment $M$, Tedeschi $V$, Valentini $R$, Grace $J$ (2007). The human footprint in the carbon cycle of temperate and boreal forests. Nature 447: 848-850. - doi: 10.1038/nature05847 Martínez-Vilalta J, Vanderklein D, Mencuccini M (2006). Tree height and age-related decline in growth in Scots pine (Pinus sylvestris L.). Oecologia 150: 529-544. - doi: 10.1007/s00442-0060552-7

McCarroll D, Loader NJ (2004). Stable isotopes in tree rings. Quaternary Science Reviews 23: 771-801. - doi: 10.1016/j.quascirev.2003.06.017

McMahon SM, Parker GG, Miller DR (2010). Evidence for a recent increase in forest growth. Proceedings of the National Academy of Sciences USA 107: 3611-5. - doi: 10.1073/pnas.0912 376107

Medlyn BE, Badeck F-W, De Pury DGG, Barton CVM, Broadmeadow M, Ceulemans R, De Angelis $P$, Forstreuter $M$, Jach ME, Kellomäki S, Laitat E, Marek M, Philippot S, Rey A, Strassemeyer J, Laitinen K, Liozon R, Portier B, Rob- erntz P, Wang K, Jstbid PG (1999). Effects of elevated $\left[\mathrm{CO}_{2}\right]$ on photosynthesis in European forest species: a meta-analysis of model parameters. Plant, Cell and Environment 22: 14751495. - doi: 10.1046/j.1365-3040.1999.00523.x

Mencuccini M, Martínez-Vilalta J, Vanderklein D, Hamid HA, Korakaki E, Lee S, Michiels B (2005). Size-mediated ageing reduces vigour in trees. Ecology Letters 8: 1183-1190. - doi: 10.1111/j.14610248.2005.00819.x

Oren R, Ellsworth DS, Johnsen KH, Phillips N, Mccarthy $H$, Ewers BE, Maier C, Scha KVR, Hendrey G, Mcnulty SG, Katul GG (2001). Soil fertility limits carbon sequestration by forest ecosystems in a $\mathrm{CO}_{2}$-enriched atmosphere. Nature 411 (6836): 469-472. - doi: 10.1038/35078064

Pavari A (1916). Studio preliminare sulla coltura delle specie forestali esotiche in Italia [Preliminar study on exotic species colture in Italy]. Annali del Regio Istituto Forestale Nazionale 7: 221. [in Italian]

Peters RL, Groenendijk P, Vlam M, Zuidema P (2015). Detecting long-term growth trends using tree rings: a critical evaluation of methods suplementary material. Global Change Biology 21 (5): 2040-2054. - doi: 10.1111/gcb.12826

Piovesan G, Biondi F, Di Filippo A, Alessandrini A, Maugeri $M$ (2008). Drought-driven growth reduction in old beech (Fagus sylvatica L.) forests of the central Apennines, Italy. Global Change Biology 14: 1265-1281. - doi: 10.1111/j.1365-2486. 2008.01570.x

R Core Team (2017). R: a language and environment for statistical computing. The R Foundation for Statistical Computing, Vienna, Austria. [online] URL: http://www.r-project.org

Rehfeldt GE, Jaquish BC, Lòpez-Upton J, SáenzRomero C, St Clair JB, Leites LP, Joyce DG (2014). Comparative genetic responses to climate for the varieties of Pinus ponderosa and Pseudotsuga menziesii: realized climate niches. Forest Ecology and Management 324: 126-137. doi: 10.1016/j.foreco.2014.02.035

Rita A, Borghetti M, Todaro L, Saracino A (2016). Interpreting the climatic effects on xylem functional traits in two Mediterranean oak species: the role of extreme climatic events. Frontiers in Plant Science 7: 1-11. - doi: 10.3389/fpls.2016.011 26

Soil Survey Staff (2014). Keys to soil taxonomy ( $12^{\text {th }}$ edn). USDA-Natural Resources Conservation Service, Washington, USA, pp. 190-195.

Thornthwaite C (1948). An approach toward a rational classification of climate. Geographical Review 38: 55-94. - doi: 10.2307/210739

Vicente-Serrano SM, Beguería S, López-Moreno JI (2010). A multiscalar drought index sensitive to global warming: the standardized precipitation evapotranspiration index. Journal of Climate 23: 1696-1718. - doi: 10.1175/2009JCLI29 09.1

Vicente-Serrano SM, Camarero JJ, Azorin-Molina C (2014). Diverse responses of forest growth to drought time-scales in the Northern Hemi- sphere. Global Ecology and Biogeography 23: 1019-1030. - doi: 10.1111/geb.12183

Vitas A, Zeimavičius K (2006). Trends of decline of Douglas fir in Lithuania: dendroclimatological approach. Baltic Forestry 12: 200-208. [online] URL: http://www.dendrochronology-lt. com/publikacijos/2006-5.pdf

Walker LR, Wardle DA, Bardgett RD, Clarkson BD (2010). The use of chronosequences in studies of ecological succession and soil development. Journal of Ecology 98: 725-736. - doi: 10.1111/j.13 65-2745.2010.01664.x

Wigley TML, Briffa KR, Jones PD (1984). On the average value of correlated time series, with applications in dendroclimatology and hydrometeorology. Journal of Climate and Applied Meteorology 23 (2): 201-213. - doi: 10.1175/1520-04 50(1984)023<0201:OTAVOC>2.0.CO;2

Wood SN (2006). Generalized additive models: an introduction with R. Chapman and Hall/CRC, New York, USA, pp. 119-150.

Yue C, Kohnle U, Hanewinkel M, Klädtke J (2011). Extracting environmentally driven growth trends from diameter increment series based on a multiplicative decomposition model. Canadian Journal of Forest Research 41: 1577-1589. doi: 10.1139/x11-056

Zang C, Biondi F (2015). Treeclim: an R package for the numerical calibration of proxy-climate relationships. Ecography 38: 431-436. - doi: 10.11 11/ecog.01335

Zhao M, Running SW (2011). Response to comments on "Drought-induced reduction in global terrestrial net primary production from 2000 through 2009". Science 333: 1093-1093. - doi: $10.1126 /$ science. 1199169

\section{Supplementary Material}

Fig. S1 - Daniels competition index calculated for trees in each plot from repeated surveys data.

Fig. S2 - Long-term variation in stand density in study plots, as derived from successive surveys.

Fig. S3 - Selection of monthly climatic variables to be included in the analysis.

Fig. S4 - Concurvity (collinearity for non-linear regression techniques) between smooth functions of selected GAMM covariates: age, Standardized Precipitation Evapotranspiration Index (SPEI) for the current and previous year, temperature.

Fig. S5 - Test of GAMM results for $\log (\mathrm{BAI})$ as a function of age and environmental variables.

Tab. S1 - Attributes of each core sampled.

Link: Ravaioli_2620@supploo1.pdf 